(c) 2011 IEEE. Personal use of this material is permitted. Permission from IEEE must be obtained for all other uses, in any current or future media, including reprinting/republishing this material for advertising or promotional purposes, creating new collective works, for resale or redistribution to servers or lists, or reuse of any copyrighted component of this work in other works. 


\section{Virtual Team Role Play Using Second Life for Teaching Business Process Concepts}

\author{
Amit Rudra \\ School of Information Systems \\ Curtin University of Technology \\ Australia \\ A.Rudra@curtin.edu.au
}

\author{
Bjørn Jæger ${ }^{1,2}$ \\ ${ }^{1}$ Molde University College, Norway \\ ${ }^{2}$ School of Information Systems \\ Curtin University of Technology \\ Australia \\ bjorn.jager@himolde.no
}

\author{
Ashley Aitken \\ School of Information Systems \\ Curtin University of Technology \\ Australia \\ A.Aitken@curtin.edu.au
}

\author{
Vanessa Chang \\ School of Information Systems \\ Curtin University of Technology, Australia \\ Vanessa.Chang@curtin.edu.au
}

\author{
Berit Helgheim \\ Molde University College, Norway \\ berit.helgheim@himolde.no
}

\begin{abstract}
This paper describes the use of a virtual world environment to facilitate a role play assignment for buying and selling Enterprise Resource Planning $(E R P)$ software solutions in a distributed environment. The exercise involved the use of Second Life to facilitate the virtual presentation and meeting among the vendors and the purchaser of the software. Students playing vendors and purchase roles were organized into teams who meet, collaborate, and negotiate business transactions in the virtual environment. The aim of the experiment was to introduce students to properties of ERP-systems which are the most common software systems used by businesses, and at the same time introduce tools for virtual team collaboration in an international setting between students in Norway and Australia. This paper reports the experiences from the students' and teachers' perspectives and we give recommendations regarding the use of Second Life in role-playing exercises.
\end{abstract}

\section{Introduction}

We live in an increasingly globally competitive environment. According to the World Trade Organization (WTO) the yearly growth rate in international trade from 1960 to 2008 was around $6 \%$ which is higher than the world gross domestic product (GDP) rate of around 4\%. WTO reports that these numbers are under-estimated due to measurement problems related to the growth of international supply chains and the increase in electronically transmitted services. The growth of international supply chains has caused an increasing number of cross-border movements especially in the case of intermediate manufactured goods [21]. The latest numbers from WTO shows an accelerating trend with global trade expected to expand by $9.5 \%$ in 2010 [22].

The convergence of global business activities through the advancement in information and communication technologies (ICT) and enterprise systems have contributed to the ease and flexibility of trading in international markets. As organizations compete and expand their business in the international markets, it is expected that their activities and processes will be widely dispersed. While the organization's operational level is supported through automated international business transactions by Enterprise Systems, the management level see an increase in the use of collaborative systems to support virtual teams. A virtual team is defined as a group of people who interact through inter-dependent tasks guided by common purpose and work across space, time and organizational boundaries with links strengthened by webs of communication technologies [15]. Organizations must ensure that their employees are trained to operate on a global scale across cultures and disciplines. Employees must understand the political, economic, social, technological, legal and environmental factors associated with international business operation. It is vital that employees have skills to capture information and facilitate the flow of information to the right person at the right time; as well as have collaboration skills to function as part of a 
team. In an international business venture, this would mean that employees are 'knowledge workers' who possess multi-dimensional skills to effectively cope with the demand of multi-national operation [11].

Given the growing importance of international operations universities are obliged to embed more topics on international business operation into their curriculum. It has been a call for university programs to be more applied, more professionally oriented and of more international character $[10,11,7]$. In particular, more focus on complementary competencies in addition to core ICT skills are requested, including communication and managerial skills (ibid). We address this need by developing two collaborative assignments; one targeting the operational level with students executing business transactions in SAP for a global supply chain (described in the another paper), and one at the management level where we develop the virtual team role play described in this paper. Students from Molde University College in Norway and Curtin University of Technology in Australia participate in a procurement role play involving presentations and negotiations in a virtual world environment in Second Life. This is incorporated into information systems classes at both universities. The students participated in activities that introduced them to a collaborative tool to develop skills to cope with the demands of international organizations.

The virtual team role play selected is frequently used for addressing the complex issue of buying, implementing and using an ERP system. A student is introduced to various ERP-system characteristics in an engaging way by letting the student act as a buyer in a purchasing team or a seller in a sales team. We implemented the role play by assigning students to virtual teams interacting and communicating via Second Life. In this paper, we discuss the setup of the role play along with the students' perceptions and teachers' experiences. Finally, recommendations for future implementations are provided.

\section{Role Playing}

Role playing for educational purposes has been a characteristic of student-centred learning environments [3, 1, 6, 18]. A leading principle for us in creating learning environments is that it must increase student involvement. According to Astin p. 36 [2], 'the effectiveness of any educational policy or practice is directly related to the capacity of that policy or practice to increase student involvement.' In role playing students participate actively in learning activities. Through role play learners engage in stories that are either open ended or defined by a manuscript or a combination of both depending on the learning situations. As in our case, a combination of open ended and manuscript were used where the students demonstrate their knowledge by filling in open parts. Role play is also a social activity in which players act or take on specific roles presented to them. In doing so, players express their ideas, arguments and feelings, in their effort to convince others. Through the interaction players get the opportunity to both share their knowledge and to extend their knowledge by learning from others. Role play has a high learning value in educational domains where skills such as critical thinking, group communication, debate and decision making are of high importance. Business education and information systems management are two such domains. In classes where the emphasis is upon choices, role play exercises focusing on decision making are ideal for supporting an educator's training needs [6]. Recent developments of virtual worlds like Second Life have enabled the design of more sophisticated on-line role play environments which both mimic real world environments more closely than before, and which go beyond what is possible in real world domains $[1,9]$. In this role play there are three learning dimensions. First, students will get knowledge of different ERP systems, second, insight into selection criteria for purchasing information systems and third, the training by acting in a simulated business environment; either as sales representatives or in a purchasing team using a virtual world as a common medium.

\subsection{The Role Play Case}

The role play selected is Response to Request-ForProposal for an ERP system. It is frequently used in classes worldwide for addressing the complex issue of buying, implementing and using an ERP system as described in the text book by Sumner [17]. The context of the role play is a fictional mid-sized manufacturing company, Wingate Electric that has a set of computer applications handling their information management needs. Their applications have become fragmented over time and costly to operate and maintain, consequently the company considers buying a new ERP system to solve these problems. The new system should have functions supporting financial and accounting processes including general ledger and accounts payable/receivable, with the option of adding modules for production planning and manufacturing. The company develops a request-for-proposal which describes their needs of a new system. There are e.g. three competing ERP vendors who respond to the request-for-proposal; SAP, Microsoft and an Application Service Provider solution offered by SAP 
(SAP ByDesign). After a presentation by each vendor Wingate goes through a decision process to decide upon a winner. This basic setup can easily be adapted in various ways depending on the class size and the time available. As an example, consider a class of 16 students. They can be organized into four teams; one sales team with four members for each of the three vendors and one purchasing team with four members representing a panel of managers from Wingate Electric. One can adjust the number of sales teams, the number of participants in each team, and the amount of work they need to put in by varying what is handed out and what they have to make by themselves. A minimum preparation is when all the material needed is handed out, and a maximum is to let the students gather all sales information and make up the presentation material themselves. This collaborative effort with distributed team members gives them experience in using other communication tools like email, chat, collaborative software and social media. In turn, this will contribute to develop skills in using various virtual tools.

During the preparation each team conduct a literature search and possibly make a contact with vendors to gather information and to develop specific deliverables. This preparation phase is important for the learning outcome related to the specific topics studied (i.e. characteristics of ERP systems). The role playing activity itself is considered a strong motivational factor for the preparation. Deliverables for the purchasing team is a score card based on a set of selection criteria and a scoring method for evaluation of alternative ERP systems. Each sales team develop a sales presentation. The teams are given the company background of Wingate Electric together with the team directions, a list of roles with job titles, background of each role and pointers to literature. In the role playing act each sales team presents their ERP system while the purchasing team from Wingate Electric asks questions and use the score card to record their marks. When all the sales teams have completed their presentations the purchasing team uses scores given to decide upon a winning vendor. Before announcing the winner they provide feedback to each sales team with respect to the how effectively each presentation has addressed the selection criteria.

\subsection{Explicit and tacit knowledge}

In practice purchasing decisions are made based on both explicit and tacit knowledge. The purpose of the role play is to introduce students to basic characteristics of ERP systems together with an introduction to the purchasing decision process including the importance of teams and the use of explicit and tacit knowledge. Giunipero, Dawley and Anthony [8] found that approximately equal amounts of formal data and tacit knowledge were used in buying decisions made by purchasing managers. Tacit knowledge relates to personal experiences, it represents knowledge that is used in evaluation, points of view, commitments and decisions. This type of knowledge is difficult to articulate or codify. According to Von et al [19] a face to face interaction is the only effective and powerful means for the transfer of tacit knowledge. In a face to face setting, gestures and body language are used to display emotional reactions. Since then virtual world environment such as Second Life has emerged. This platform supports a combination of a real and a virtual presence of users. Real presence is achieved by voice communication and to some extent control of the body language including lip synchronization and a set of simple gestures of the avatar. The presence by avatars allows for simulated face to face interaction combined with real voice where ideas and knowledge are shared. In Second Life gestures and physical expression are still limited compared to a real life face to face meeting. Introducing a team-oriented role play in Second Life allows the students to meet in a common virtual place to share and express ideas. Tacit knowledge may be gained by users meeting, participating and interacting regularly. Providing regular feedback may also lead to effective transfer of tacit knowledge in a virtual world environment. In addition, a simulated business environment in Second Life can be used for training students to act in real business environments. The sessions in Second Life can also be recorded for students to review their performances.

In contrast to tacit knowledge, explicit knowledge is knowledge that has been codified [14]. Explicit knowledge in the form of vendor web sites, on-line library resources, trade publications and marketing publications provides some relevant information for a purchase manager to make a decision. Although this information is readily available, a manager or buyer requires both explicit and tacit knowledge to sufficiently close a business deal and to make a decision. Students and inexperienced purchase managers typically break social norms and misunderstand subtle cues that experienced buyers take for granted. When teaching we would like to introduce students to the importance of tacit knowledge in making purchasing decisions. Role plays have been found to be a useful technique in teaching peoplefacing skills including training purchasing and sales people.

\subsection{Role Playing in Second Life}


Second Life is an Internet-based non-gaming virtual world imagined and created entirely by its residents [23]. The primary interaction object in Second Life is an avatar which is a representation of a user. The users of Second Life are distributed all over the world and real-time interaction is possible through text, voice chatting and even embedded video tools. Second Life users can communicate, collaborate, and participate in activities and explore the virtual world through motional avatars. An avatar in Second Life has human characteristics, including speech and facial expressions which enables transfer of expressions in the affective domain. Users can also trade items and services in this environment and as such, we find Second Life a suitable medium for conducting role plays. Other technology such as video conferencing is a common technology used for distance education. However, videoconferencing does not support the concept of a common place to meet and interact when participants are in different geographical locations. Typically, the video conferencing environment facing each participant is a screen of participants in separate windows often referred to as a set of talking heads. Making efficient team presentations, performing negotiations, showing group membership and coordinating activities are difficult and ineffective in this environment. Virtual worlds, on the other hand offer the possibility of creating a common virtual place to meet. One can create realistic environments familiar to the participants and participants can easily express team membership by grouping themselves together much in the same way as in real life. At the same time they can also utilize a range of communication facilities like private and group conversations. The key features of merging 3D world, Community, Creation and Commerce (3D3C) in a virtual world environment which resemble the real-life environment allow education providers to use the virtual world environment as a role-play setting [16].

\subsection{Cost Efficient Implementation}

Second Life has the capability of creating a wide range of learning environments in a cost efficient way compared with real life environments. A real life role play would be substantially more expensive due to the costs of co-locating participants, allocate or rent professional meeting rooms, changing the appearance of the academics into a business style, and setting up studio recording capabilities. A further promising opportunity in a virtual world environment is the possibility to invite guest experts from other organizations and businesses at virtually no monetary cost. In this way, professionals can participate in role plays which make it possible for students to interact directly with business experts. In the few studies that have reported involvement of virtual guest experts in mediated teaching environments found that students were excited by the opportunity to hold discussions with the guest hosts, and vice versa; the guests were positive to spend time doing the interaction [14, 20].

In the preparation of the role play, professionals in four Norwegian companies were asked to participate in the role-play. All of them agreed to participate as guest experts at no cost to the two universities. However we chose to use only one of the companies to ease the coordination required and to get experience. All of the professionals had experience from using ERP systems and from buying and selling large complex software systems. The four companies asked were DnB NOR, Ernst and Young, The Norwegian Labour and Welfare Administration (NAV) and Wise Consulting. The professionals were enthusiastic and excited to be using Second Life to have direct contact with the students. Apart from the corporate social responsibility of the four companies, they also felt that by participating, there was a possibility of recruiting new employees, it would enable them to test new innovative business opportunities, and experiment with the use of Second Life as a collaborative tool for team work.

\section{Methodology}

We base our development of the learning environment on an iterative problem solving paradigm that seeks to create innovations using information systems where design is seen as both a process and a product. The learning environment is our design product and our design process consists of the activities design, run and evaluate as illustrated in Figure 1.

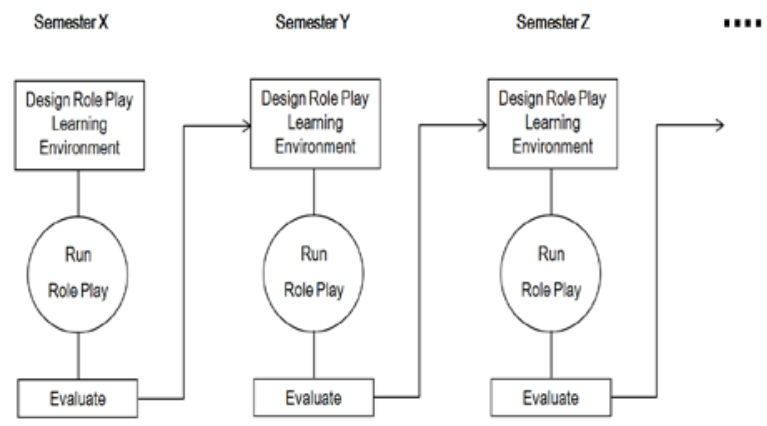

Figure 1. Method for development of the learning environment over several semesters

The evaluation provides feedback and a better understanding of the learning environment in order to improve both the environment and the role play 
assignment. We used a qualitative approach combining three methods. One method was a questionnaire with both numbered answer alternatives and open ended questions. The questionnaire was used to get an impression of student perceptions and their reflections on using Second Life for the role play. A second method was discussions with students and teachers at both campuses to get their perceptions and experiences. The third method is the use of playback of recorded sessions in Second Life to support feedback. Second Life, being a mediated technology via a PC, inherits the intrinsic property of mediated technologies that they can be recorded, stored and played back with little effort and small costs. Recording is not an option in Second Life, but one can use screen recording programs that records all activities including sound into a movie file. Popular recording tools are Camtasia [4] and Fraps [5]. This enables a post-exercise reflection of the virtual-experience and a debriefing of the experiences which is important for the learning outcome [6], and in addition it provides valuable feedback to teachers and learning environment designers.

The design-run-evaluate sequence in Figure 1 is repeated over several semesters. It goes on as long as the role playing takes place to incorporate technological innovations and lessons learned from each previous semester. In this paper we report on our experiences from the most recent semester (FebruaryApril 2010) where we included international collaboration.

\section{The Role Play Experiment}

As described previously, role play is an effective pedagogical strategy frequently used in information systems and business classes for addressing complex problem solving issues. The role play exercise involving the buying, implementing and using an ERP system is described in Sumner [17]. Sumner conducted a similar role play at Molde University College in 2005, 2006 and 2007.

The manuscript describes a separate meeting between business executives in a purchasing firm and the senior sales executives from three the vendors SAP, Microsoft and SAP ByDesign. Typically, this type of meeting is held in a high-end executive meeting room since buying an ERP system often is the single largest investment a company does with a time horizon of ten to twenty years. As shown in Figure 2, an executive meeting room was created in Second Life to make the role play realistic.

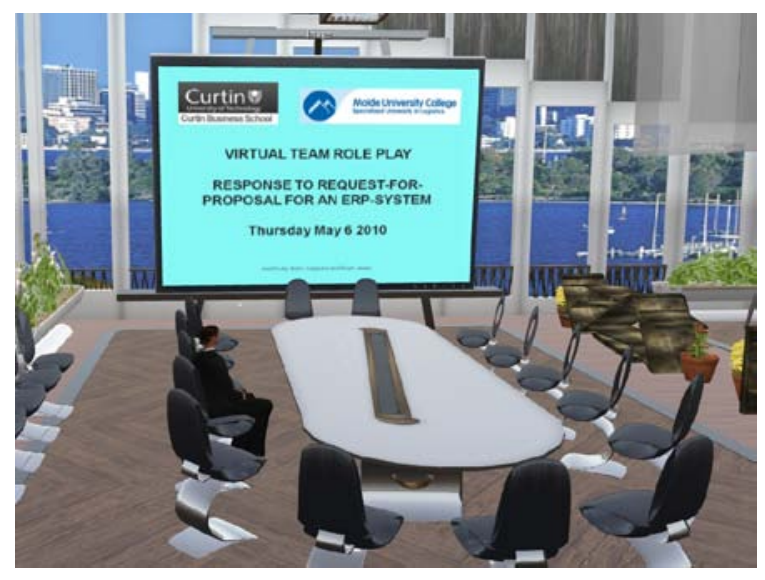

Figure 2. The executive meeting room used at the Kamimo virtual campus in Second Life

Students from one class in Molde, Norway and one class in Perth, Australia participated in the same role play forming true virtual teams.

As we adhere to the realistic nature of the role play exercise, the students were asked to familiarize themselves with the business etiquettes and code of conduct required in business dealings and negotiations. This includes requiring avatars to have a formal dress code in a typical executive style aligned with the real world environment. The students were provided with suitable business wardrobes to select from. Avatar appearance is one cue from the real world that can be mimicked in the virtual world. We assume that the first impression largely defines "who" an avatar is - the three-second first-impression - just like in the real world. Some examples of the professionally dressed avatars are shown in Figure 3.

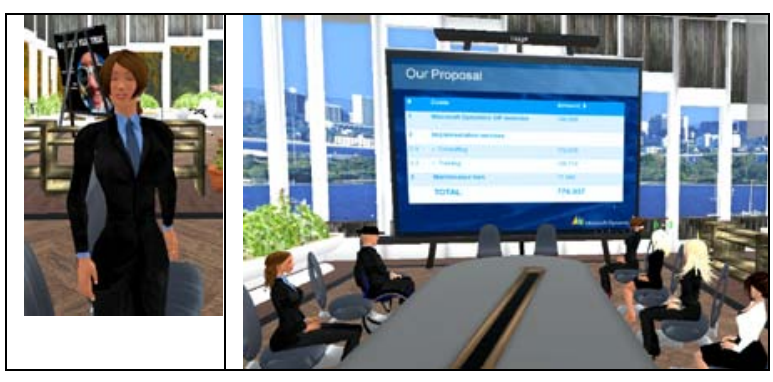

Figure 3. Examples of avatars with business appearance

By using a replica of a traditional business environment the students can quickly become familiar with the environment letting them concentrate on the presentations and the negotiations in order to develop skills in persuasion, timing, and sequencing.

The students in Norway and Australia did not know each other beforehand which made the virtual team 
role play more realistic. Doing the role play in Second Life was voluntary. The ones who did not participate had to do the role play in a classroom. All 22 students in Molde volunteered for Second Life while 6 of 24 students in Perth joined giving a total of 28 students. The students in Perth formed two sales teams. The rest of the teams were in Molde. Figure 4 showes the sales team from SAP Business ByDesign presenting in Second Life virtual environment to the students. Note how the virtual teams can present slides in Second Life just as they would in a real world presentation. The support in second life for private voice and/or chat is useful when someone wants to communicate without disturbing an ongoing presentation. We found this a particularly useful feature for teachers from Norway and Australia which observed the role play via their avatars, since we could coordinate activities without interfering with the student activities. This is impossible with other technologies like video conferencing or in real life.

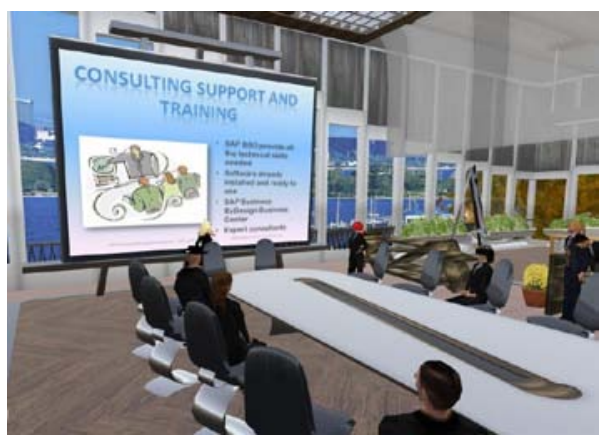

Figure 4. Snap-shot of from the presentation by the sales team from SAP Business ByDesign

\section{Evaluation}

The method used was a combination of informal discussions with teachers and students and a questionnaire together with feedback from recordings of the sessions. A 7-point Likert scale was used for the numbered answer alternatives. The students were also given an opportunity to provide as many comments as they desired. All six in Perth and eighteen of the 22 students in Molde answered the questionnaire giving a total of 24 respondents. The questions with numbered alternatives for the answer, the scales and the average results of answers are given in Table 1.

Table 1. Questions with numbered alternatives, the scales and the average result of answers

\begin{tabular}{|l|l|l|l|}
\hline Question & $\begin{array}{l}\text { A. My general } \\
\text { impression of using }\end{array}$ & $\begin{array}{l}\text { B. When doing the } \\
\text { role play I experienced }\end{array}$ & $\begin{array}{l}\text { C. As compared to } \\
\text { traditional (face-to- }\end{array}$ \\
& $\begin{array}{l}\text { Second Life for } \\
\text { a feeling of presence }\end{array}$ & $\begin{array}{l}\text { face) projects on } \\
\text { doing a Virtual }\end{array}$ & with the other \\
campus the
\end{tabular}

\begin{tabular}{|c|c|c|c|}
\hline & $\begin{array}{l}\text { Team Role Play is } \\
\text { that it's }\end{array}$ & participants _ & $\begin{array}{l}\text { workload in } \\
\text { preparing for the } \\
\text { role play in Second } \\
\text { Life required }\end{array}$ \\
\hline Scale & $\begin{array}{l}\text { 1.Totally useless } 2 . \\
\text { Useless 3. Mostly } \\
\text { useless 4.Useful } 5 . \\
\text { Useful, this can be } \\
\text { used by real } \\
\text { businesses } 6 . \text { Very } \\
\text { useful } 7 \text {. An } \\
\text { indispensable tool }\end{array}$ & $\begin{array}{l}\text { 1. Not at all } 2 \text {. Only } \\
\text { to a very small extent } \\
3 \text {. Somewhat } 4 \text {. Yes, I } \\
\text { got a feeling of } \\
\text { presence with the } \\
\text { others } 5 \text {. I got a good } \\
\text { feeling of presence. } 6 \text {. } \\
\text { It was almost like in } \\
\text { real life } 7 \text {. Just like } \\
\text { real life }\end{array}$ & $\begin{array}{l}\text { 1. Quite a lot more } \\
\text { work 2. Much } \\
\text { more work } 3 \text {. More } \\
\text { work 4. About the } \\
\text { same amount of } \\
\text { work 5. Less work } \\
\text { 6. Much less work } \\
\text { 7. Quite a lot less } \\
\text { work }\end{array}$ \\
\hline Molde & 4,9 & 4,4 & 4,5 \\
\hline Perth & 5,2 & 4,3 & 5,2 \\
\hline $\begin{array}{l}\text { Combin } \\
\text { ed }\end{array}$ & 5,1 & 4,4 & 4,8 \\
\hline
\end{tabular}

As the results in Molde and Perth are nearly identical so we discuss the combined results for Molde and Perth (the last row). Question A got 5.1 showing that the students considered the role play as useful and that it could be used by real businesses. Question B got 4.4 showing that the students perceived that they got a feeling of presence / got a good feeling of presence.

For question $\mathrm{C}$ the students considered the amount of work required for the role play in Second Life as about the same or less than performing the role play in real life. We conclude that the students show a positive attitude towards using Second Life for a virtual team role play. This is especially so when we consider the minimal exposure and training in Second Life (approx a total of one hour) before the role play.

Some students gave additional comments on the open-ended questions. Positive comments were:

- I learnt something useful this way. My attitude towards Second Life is quite positive.

- It (Second Life) has many advantages and provides a good feeling of presence, as it is 3-D.

- Gives a feeling of presence and of real life. A very good experience.

- No stage fright to worry about. So easier to time presentation precisely.

- I did not have any faith in it when we made our Avatar but was impressed when we did our presentation.

- It was quite a new experience.

- It was efficient and real-time business decision making.

Some cautionary comments:

- I think a requirement for it (Second Life) to work in practice is that the participants have established a relation before its use.

- This means the participants have met each other and created a minimum level of confidence.

- It also depends on what will be at stake. That is, what significance such a "meeting" will have. What consequences will consensus have for the remaining part of the process?

- Will there be any form of doubt? 
- Do the participants need a new round of clarification, explanations regarding the contents of the meeting?

- I would get best training for this type of assignment.

- Feeling of distance was less than expected.

While most were quite enthusiastic, there were some who reported issues and concerns:

- You don't have the feeling of seeing the person and his/her facial expressions.

- Need better internet connection. Sometime it does not work because of the distance.

- Bad sound and fast talking presenters - I had problems to get everything that was said.

\section{Recommendations}

A virtual environment (like Second Life) is clearly an interesting arena for running virtual team role plays. Based on our experiences we provide some recommendations regarding the design, setup and conduction of a virtual team role play in Second Life.

\subsection{Voice Chat Setup and Features}

o Voice is the most important communication feature for the role play. However, the voice service in Second Life is not a straight forward plug-and-play service. Special considerations must be taken for the setup of PCs, the headsets and the microphone configuration in Second Life. Detailed information on how to do this are reported numerous places that can be found on the web, including the Second Life site.

\subsection{Record the Second Life Role Playing Sessions}

o Use an external recording tool like Camtasia [4] or Fraps [5]

o In a standard PC with one sound card one cannot be talking in Second Life at the same time as voice chat is recorded.

o Use a separate PC and avatar for recording, or buy a sound card with multiple I/O channels.

\subsection{Training}

Participants should be trained to handle the voice chat and its group conversation features, how to upload and display presentations in Second Life. Otherwise, our experience is that the remaining skills needed like basic movements, sitting at the table and zooming to the presentation are easy to learn in a few minutes on their own. Another issue not directly related to the virtual environment as such is that participants should rehearse and prepare well for the role play in order to feel comfortable in the situation increasing the likelihood for an immersive experience. A short "Code of Conduct in Second Life" seminar in Second Life should be provided to all participants.

\subsection{Let Each Participant Connect to SL from a Separate Physical Room}

In order to create an immersive situation it is important to reduce the number of distracting cues both in the physical environment used when connecting to Second life, and in the virtual environment in Second Life itself. To achieve this we found that arranging for on-campus students to connect to Second life from separate physical locations is a good approach.

Using a computer lab with several active participants logged in to Second Life is not good since the voice in Second Life is delayed compared with the voice in the lab, making it hard to concentrate on the role playing.

\subsection{Virtual Meeting Room Setup and Access Rules}

As the virtual environment is used for collaboration, negotiation and presentation, the space in Second Life should be set to serve this purpose. Entrance to the meeting room should be by invitation only. Especially, in a teaching environment it is tempting for non-participating students to hang around in Second Life to observe the role play. However, since watching others is a good way to get familiar with the role playing situation we offer recordings of previous sessions for the students to play back.

To reduce the time to get a Second Life account, an avatar, and dress-up one can provide a set of pre-made avatars to the students, but this will be at the cost of less training in the virtual environment during setup.

\section{Final Remarks and Conclusion}

We found that students have adopted both tacit and explicit knowledge by participating in the virtual team role play in Second Life. As in real life, a thorough and comprehensive preparation is required by the students in order to get a successful learning outcome. We found that the students easily handled the technical operation of Second Life for use in the role play. However there were two major issues that were 
constant challenges. One was getting voice chat to work and maintaining it over time. The other was that the Second Life client runs on PCs only with certain types of graphic card. We consider these issues as a result of the contemporary technology used and that they will disappear as the technology evolves. Lastly, we observed that by bringing in students from other universities the atmosphere became more formal, more focused, and more like in a real business environment. In conclusion, using Second Life to conduct virtual team role play is found to contribute to develop skills in handling global business operations.

\section{References}

[1] Aldrich, C. (2005). Learning by doing. San Francisco. CA. Pfeiffer.

[2] Astin, A. W. (1985). Involvement: The cornerstone of excellence. Change, 17(4): 35-39.

[3] Bloom, B.S. (1956). The Taxonomy of Educational Objectives: Classification of Educational Goals Handbook 1: The Cognitive Domain. New York: McKay Press.

[4] Camtasia. (2010). Last retrieved 15th June 2010 at: www.softwarecasa.com/

[5] Fraps. (2010). Last retrieved 15th June 2010 at: www.fraps.com

[6] De Freitas, S. (2006) Learning in Immersive worlds. Joint Information Systems Committee (JISC) e-Learning Programme, UK. Last retrieved 15th September 2008 at: http://www.jisc.ac.uk/media/documents/programmes/elearnin ginnovation/gamingreport_v3.pdf

[7] eSkills Demand (2009) Demand Developments and Challenges, Sectoral e-Business Watch Study Report No. 05/2009, European Union.

[8] Giunipero, L., Dawley, D., and Anthony W. P. (1999). "The Impact of Tacit Knowledge on Purchasing Decisions," The Journal of Supply Chain Management, vol.35, no. 1, pp. 42-49, 1999.

[9] Jones, S. (2007). “Adding value to online role plays: Virtual situated learning environments”, Proceedings of Ascilite, Singapore 2007.

[10] Harvard (2008). Harvard Business School Discusses Future of the MBA, Harvard Bulletin http://www.exed.hbs.edu/cgi-bin/wk/6053.html
[11] Hasanali, F 2002, 'Critical Success Factors of Knowledge Management', Retrieved October 1, 2009, from http://www.providersedge.com/docs/km_articles/Critical_suc cess_factors_of_KM.pdf

[12] Helfert, M. (2008). "Business Informatics: An Engineering Perspective on Information Systems,” Journal of Information Technology Education, Vol. 7. 2008.

[13] Hevner, A., March, S., Park, J., Ram, S.: Design Science in Information Systems Research. MIS Quarterly 28, pp. 75-105 (2004)

[14] Kumari (2001). Connecting graduate students to virtual guests through asynchronous discussions - Analysis of an experience. Journal of Asynchronous Learning Networks, 5(2), 53-63.

[15] Lipnack, J. and Stamps, (1997). Virtual teams. New York: John Wiley and Sons, Inc.

[16] Sivan, Y. (2008). 3D3C Real Virtual Worlds Defined: The Immense Potential of Merging 3D, Community, Creation, and Commerce, Journal of Virtual Worlds Research: Past, Present \& Future. Retrieved October 1, 2009 from http://journals.tdl.org/jvwr/article/viewArticle/278

[17] Sumner, M. (2005). Enterprise Resource Planning, Prentice Hall, 2005.

[18] Vasileiou, V. N., and Paraskeva, F.. (2010). "Teaching Role-Playing Instruction in Second Life: An Explorative Study", Journal of Information, Information Technology and Organizations, vol 5.

[19] Von, K.G., K. Ichijo and I. Nonaka, 2000. Enabling Knowledge Creation: How to Unlock the Mystery of Tacit Knowledge and Release the Power of Innovation. Oxford University Press, Oxford, New York, pp: 292.

[20] Wearmouth J., Smith, A.P., and Soler, J. (2004). Computer conferencing with access to a 'guest expert' in the professional development of special educational needs coordinators. British Journal of Educational Technology, 35(1), 81-93.

[21] WTO (2009). World Trade Developments, World Trade Organization (WTO). http://www.wto.org/english/res_e/statis_e/its2009_e/section1 _e/its09_highlights1_e.pdf

[22] WTO (2010). International Trade Statistics, Press Releases, Press/598, Retrieved 26 March 2010 from http://www.wto.org/english/news_e/pres10_e/pr598_e.htm [23] Linden Labs (2009). Second Life - What is Second Life? Linden Lab, San Francisco, USA, last retrieved 22 August, 2009 from http://secondlife.com/whatis/ 